\title{
Evaluation of cardiovascular risk in adults with type 1 diabetes: poor concordance between the 2019 ESC risk classification and 10-year cardiovascular risk prediction according to the Steno Type 1 Risk Engine
}

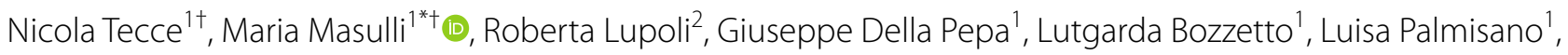
Angela Albarosa Rivellese ${ }^{1}$, Gabriele Riccardi ${ }^{1}$ and Brunella Capaldo ${ }^{1}$

\begin{abstract}
Background: Patients with type 1 diabetes (T1D) have higher mortality risk compared to the general population; this is largely due to increased rates of cardiovascular disease (CVD). As accurate CVD risk stratification is essential for an appropriate preventive strategy, we aimed to evaluate the concordance between 2019 European Society of Cardiology (ESC) CVD risk classification and the 10-year CVD risk prediction according to the Steno Type 1 Risk Engine (ST1RE) in adults with T1D.

Methods: A cohort of 575 adults with T1D (272F/303M, mean age $36 \pm 12$ years) were studied. Patients were stratified in different CVD risk categories according to ESC criteria and the 10-year CVD risk prediction was estimated with ST1RE within each category.

Results: Men had higher BMI, WC, SBP than women, while no difference was found in $\mathrm{HbA1}$ c levels between genders. According to the ESC classification, $92.5 \%$ of patients aged $<35$ years and $100 \%$ of patients $\geq 35$ years were at very high/high risk. Conversely, using ST1RE to predict the 10-year CVD risk within each ESC category, among patients at very high risk according to ESC, almost all (99\%) had a moderate CVD risk according to ST1RE if age $<35$ years; among patients aged $\geq 35$ years, the majority (59.1\%) was at moderate risk and only $12 \%$ had a predicted very high risk by ST1RE. The presence of target organ damage or three o more CV risk factors, or early onset T1D of long duration ( $>20$ years) alone identified few patients $(<30 \%)$ among those aged $\geq 35$ years, who were at very high risk according to ESC, in whom this condition was confirmed by ST1RE; conversely, the coexistence of two or more of these criteria identified about half of the patients at high/very high risk also according to this predicting algorithm. When only patients aged $\geq 50$ years were considered, there was greater concordance between ESC classification and ST1RE prediction, since as many as 78\% of those at high/very high risk according to ESC were confirmed as such also by ST1RE.
\end{abstract}

*Correspondence: maria.masulli@unina.it

${ }^{\dagger}$ Nicola Tecce and Maria Masulli contributed equally to this article and share co-first authorship

${ }^{1}$ Department of Clinical Medicine and Surgery, Federico II University, Via

S. Pansini 5, 80131 Naples, Italy

Full list of author information is available at the end of the article

c) The Author(s) 2020. This article is licensed under a Creative Commons Attribution 4.0 International License, which permits use, sharing, adaptation, distribution and reproduction in any medium or format, as long as you give appropriate credit to the original author(s) and the source, provide a link to the Creative Commons licence, and indicate if changes were made. The images or other third party material in this article are included in the article's Creative Commons licence, unless indicated otherwise in a credit line to the material. If material is not included in the article's Creative Commons licence and your intended use is not permitted by statutory regulation or exceeds the permitted use, you will need to obtain permission directly from the copyright holder. To view a copy of this licence, visit http://creativeco mmons.org/licenses/by/4.0/. The Creative Commons Public Domain Dedication waiver (http://creativecommons.org/publicdomain/ zero/1.0/) applies to the data made available in this article, unless otherwise stated in a credit line to the data. 
Conclusions: Using ESC criteria, a large proportion (45\%) of T1D patients without CVD are classified at very high CVD risk; however, among them, none of those $<35$ years and only $12 \%$ of those $\geq 35$ years could be confirmed at very high CVD risk by the ST1RE predicting algorithm. More studies are needed to characterize the clinical and metabolic features of T1D patients that identify those at very high CVD risk, in whom a very aggressive cardioprotective treatment would be justified.

Keywords: Type 1 diabetes, Cardiovascular risk, STENO Type 1 risk engine, ESC guidelines

\section{Background}

Worldwide estimates of numbers of individuals with Type 1 diabetes (T1D) continue to increase [1]. Among other reasons, this is particularly worrisome since adults with T1D have an almost threefold higher mortality compared to the general population, largely due to premature cardiovascular disease (CVD) [2-7]. In this respect, even in children and young adults with T1D, there is evidence of cardiac and vascular dysfunction, as supported by the presence of abnormal global myocardial function, stiffening of large arteries, and early atherosclerosis [8].

Hyperglycemia plays an important role in the onset and progression of vascular damage and, as demonstrated by DCCT/EDIC study, improving glycemic control substantially reduces the risk of microvascular complications and CVD [9]. However, according to more recent data from the Swedish National Diabetes Register, patients with T1D and a glycated hemoglobin level of $6.9 \%$ or lower still have a twofold risk of death compared to matched controls [2]. These findings, together with the evidence from randomized clinical trials (RCTs) [9] support the concept that, in addition to glycemic control, other factors concur to increase CVD incidence in these patients [9-12]. In fact, the risk of ischemic and hemorrhagic stroke rises linearly with blood pressure levels in individuals with T1D; this is already evident at values below the current treatment goals of $130 / 80 \mathrm{mmHg}$ [13]. Moreover, the presence and severity of microvascular complications contribute to increase the risk of all-cause mortality and CVD outcomes in these patients [14]. As to the effects of pharmacological interventions on $\mathrm{CV}$ risk factors, at odds with type 2 diabetes (T2D), only very few RCTs have assessed the impact of this strategy on the incidence of CVD outcomes in T1D patients-well characterized for their clinical and metabolic features-in a primary prevention setting $[15,16]$. Thus, at present, the stratification of CVD risk in T1D patients is mainly based on observational data [10].

In 2019, updated guidelines for the management and prevention of CVD risk in individuals with diabetes have been issued by the European Society of Cardiology (ESC) [17]. According to ESC criteria, most T1D patients-in the absence of previous CVD-are at high/very high risk [17]. This has a major impact on the clinical care of these patients, particularly younger ones, since it implies not only very ambitious targets for LDL-cholesterol, often achievable only with aggressive treatment strategies, including the very expensive therapies now available, but also more stringent blood pressure control and the use of antiplatelet agents [18]. Therefore, it would be desirable to identify relevant features of T1D patients that characterize the presence of higher CVD risk to identify those who would qualify for a more aggressive treatment of CVD risk factors.

To this aim, risk scores and other CVD biomarkers have been developed for the risk stratification of T1D patients [19-25]. The American Diabetes Association (ADA) strongly supports their utilization for the assessment of the 10-year risk of a first CVD event to help guide treatment strategy [26]. Among these, a recently published CVD prediction model-the Steno Type 1 Risk Engine (ST1RE) - has shown a high performance in predicting 10-year CVD events in a cohort of 4996 T1D adults without previous CVD events [23], and also in identifying T1D patients with preclinical atherosclerosis $[27,28]$.

Against this background, the aim of the present study was to evaluate the concordance between 2019 ESC CVD risk classification and 10-year CVD risk predicted by ST1RE in a cohort of unselected T1D patients without previous CVD. We focused particularly on the very high risk category because of the strict recommended targets for CVD risk factors, requiring high intensity cardio-protective therapy.

\section{Methods}

\section{Study design and population}

This is an observational retrospective, single-center study in a cohort of five hundred seventy-five individuals with T1D (272F/303M, age range $18-74$ years). All participants attended the Outpatient Diabetes Clinic of Federico II University Hospital, Naples (Italy) from January 2015 to December 2018; they underwent yearly evaluation for the routine screening of chronic complications. The medical records of each patient's most recent visit were reviewed to collect clinical and biochemical variables: body mass index (BMI), waist circumference (WC), systolic blood pressure (SBP), diastolic blood 
pressure (DBP), lipid profile (total cholesterol, HDL cholesterol, triglycerides), duration of diabetes, insulin therapy, smoking status, physical activity, presence of target organ damage (proteinuria, renal impairment defined as eGFR $<30 \mathrm{ml} / \mathrm{min} / 1.73 \mathrm{~m}^{2}$, left ventricular hypertrophy, or retinopathy), presence of chronic diabetic complications, comorbidities, other autoimmune diseases (autoimmune thyroiditis, celiac disease, Addison disease, systemic lupus erythematosus, vitiligo) and medication use.

\section{Measurements and definitions}

Plasma concentrations of glucose and lipids were measured by standard methods; glycated hemoglobin (HbA1c) by High-performance liquid chromatography (HPLC); albumin concentration in spot urine by immunonephelometry, and plasma and urine creatinine by the modified Jaffé reaction using an autoanalyzer (Pentra 400, Horiba ABX Diagnostics). All biochemical analyses were centralized and were performed under appropriate quality control.

BMI was calculated as weight in $\mathrm{kg} /$ height in $\mathrm{m}^{2}$. Low density lipoprotein (LDL) - cholesterol was calculated by Friedwald's formula. eGFR was calculated using the CKD-EPI formula. Smoking status was defined as smoking one or more cigarettes per day. Physical exercise was defined as a dichotomic variable $(1=$ if the patient exercised more than $30 \mathrm{~min}$ per day; $0=$ if the patient exercised less than $30 \mathrm{~min}$ per day). Hypertension was diagnosed as $\mathrm{SBP} \geq 140 \mathrm{mmHg}$ or $\mathrm{DBP} \geq 90 \mathrm{mmHg}$ and/ or use of antihypertensive drugs [29]. Hypercholesterolemia was defined as LDL cholesterol $>100 \mathrm{mg} / \mathrm{dl}$ or use of cholesterol-lowering drugs.

\section{Cardiovascular risk assessment}

CVD risk categories were defined according to 2019 ESC guidelines, which classify T1D patients into 3 categories: (1) very high CVD risk ( $\geq 10 \% 10$-year risk of fatal CVD events), which includes patients who have a previous CVD, or with target organ damage, or three or more major CVD risk factors, or early-onset T1D of long duration (> 20 years); (2) high risk (5-9\% 10-year risk of fatal CVD), which comprises all patients not included in the very high or the moderate risk category, and (3) moderate risk (3-4\% 10-year risk of fatal CVD events), which includes young patients (aged $<35$ years) with T1D duration $<10$ years without other CVD risk factors. To convert the risk of fatal to that of total (fatal+ non fatal) CVD, the former was multiplied by 3 in men and by 4 in women, as suggested by ESC [18].

To evaluate the concordance between the ESC risk classification and the ST1RE prediction model, we analyzed the very-high risk category first as a whole and then separately for each subcategory according to the presence of: (a) target organ damage (proteinuria, eGFR $<30 \mathrm{~mL} /$ $\min / 1.73 \mathrm{~m}^{2}$, left ventricular hypertrophy, or retinopathy); (b) three or more risk factors (age $>35$ years, hypertension, hypercholesterolemia, smoking, obesity); (c) early-onset T1D of long duration ( $>20$ years) or a combination of these. Within each risk category, the prediction of the 10-year risk of a first fatal/non-fatal CVD event was performed using ST1RE, which employs a composite end point including ischemic heart disease, ischemic stroke, heart failure, and peripheral artery disease. In addition to traditional CVD risk factors such as age, sex, SBP, LDL-cholesterol, eGFR, smoking, ST1RE considers some variables more related to diabetes status, such as diabetes duration, $\mathrm{HbA1c}$, albuminuria, and physical exercise [23]. For our analyses, this model was applied in 532 patients since 22 had previous CVD and for 21 patients some data were missing.

\section{Assessment of microvascular complications}

Microalbuminuria was defined as urinary albumin excretion rate $(\mathrm{UAE})>30 \mathrm{mg} / \mathrm{L}$ in at least three $24 \mathrm{~h}$-urine samples obtained at about three months' intervals in the year preceding recruitment. eGFR was estimated using the CKD-EPI formula. Diabetic nephropathy was defined as two or more positive microalbuminuria test results (UAE of 3-30 $\mathrm{mg} / \mathrm{mmol}$ on spot urine) within 6 months. Autonomic neuropathy was evaluated by means of standardized cardiovascular reflex tests: parasympathetic function with beat-to-beat variation test, and sympathetic function with the blood pressure response to standing (a fall in systolic blood pressure of at least $30 \mathrm{mmHg}$ when the patient moved from the sitting to the standing position was considered diagnostic). Peripheral neuropathy was diagnosed according to the "Michigan Neuropathy Screening Instrument" based on the clinical evaluation of bilateral vibration perception test, ankle reflex assessments and tactile perception with the Semmes-Weinstein monofilament.

\section{Statistical analysis}

Data are expressed as mean \pm standard deviation (SD) or proportion (\%). To compare continuous variables, an independent samples $t$ test was performed. The Chi square test was used to analyze categorical data. A twoside $p$ value $<0.05$ was considered significant. The Statistical analysis was performed using SPSS v.22 (SPSS, Inc. Chicago, IL USA).

\section{Results}

The main clinical and metabolic characteristics of the study population are shown in Table 1. Men had significantly higher values of BMI, WC, SBP, DBP than women 
Table 1 General characteristics of the study population

\begin{tabular}{|c|c|c|c|c|}
\hline & $\begin{array}{l}\text { Total } \\
n=575\end{array}$ & $\begin{array}{l}\text { Females } \\
n=272\end{array}$ & $\begin{array}{l}\text { Males } \\
n=303\end{array}$ & $\mathbf{P}$ \\
\hline Age (years) & $36 \pm 12$ & $36 \pm 13$ & $35.6 \pm 12.1$ & 0.789 \\
\hline Diabetes duration (years) & $19 \pm 11$ & $19.1 \pm 10.5$ & $18.8 \pm 10.9$ & 0.739 \\
\hline Early onset T1D (1-10 years of age) (\%) & 31.3 & 32.4 & 30.4 & 0.653 \\
\hline Age of T1D onset (years) & $16.8 \pm 10.8$ & $16.7 \pm 11.1$ & $17 \pm 10.4$ & 0.712 \\
\hline Waist circumference (cm) & $86.0 \pm 11.8$ & $82.4 \pm 11.3$ & $89.3 \pm 11.2$ & $<0.0001$ \\
\hline BMI $\left(\mathrm{kg} / \mathrm{m}^{2}\right)$ & $25.1 \pm 3.6$ & $24.7 \pm 3.8$ & $25.4 \pm 3.3$ & 0.018 \\
\hline HbA1c (\%) & $7.7 \pm 1.2$ & $7.9 \pm 1.2$ & $7.7 \pm 1.22$ & 0.064 \\
\hline SBP $(m m H g)$ & $121 \pm 16$ & $118 \pm 17$ & $123 \pm 14$ & $<0.0001$ \\
\hline $\mathrm{DBP}(\mathrm{mmHg})$ & $75 \pm 10$ & $73 \pm 11$ & $76 \pm 9$ & 0.001 \\
\hline Total cholesterol (mg/dl) & $178 \pm 34$ & $181.5 \pm 35.7$ & $175.6 \pm 33$ & 0.040 \\
\hline LDL-cholesterol (mg/dl) & $101 \pm 29$ & $100 \pm 28.1$ & $101.5 \pm 29.5$ & 0.468 \\
\hline HDL-cholesterol (mg/dl) & $62 \pm 16$ & $68 \pm 17.3$ & $56.9 \pm 13.9$ & $<0.0001$ \\
\hline Triglycerides (mg/dl) & $79 \pm 52$ & $71.2 \pm 36.7$ & $86.5 \pm 62.3$ & $<0.0001$ \\
\hline eGFR (CKD-EPI) (ml/min/1.73 m²) & $101.8 \pm 18$ & $100.7 \pm 18.6$ & $102.8 \pm 17.5$ & 0.168 \\
\hline Other autoimmune diseases (\%) & 35 & 44.9 & 25.4 & $<0.0001$ \\
\hline CSII (\%) & 32.5 & 38.7 & 26.9 & 0.003 \\
\hline Microvascular complications (\%) & 27.7 & 26.8 & 28.4 & 0.679 \\
\hline Nephropathy (\%) & 9.7 & 9.4 & 10.1 & 0.778 \\
\hline Retinopathy (\%) & 18.8 & 15.2 & 22.1 & 0.038 \\
\hline Neuropathy (\%) & 10.4 & 10.9 & 10.07 & 0.727 \\
\hline Previous CVD (\%) & 3.8 & 3.3 & 4.3 & 0.540 \\
\hline Hypertension (\%) & 29.4 & 25.4 & 33 & 0.050 \\
\hline Hypercholesterolemia (\%) & 53 & 49.6 & 56.1 & 0.132 \\
\hline
\end{tabular}

Data are expressed as Mean \pm standard deviation or as a percentage

SBP systolic blood pressure, DBP diastolic blood pressure, CVD Cardiovascular disease (Ischemic heart disease, stroke, peripheral arteriopathy), eGFR estimated glomerular filtration rate, CS/l continuous subcutaneous insulin infusion

$(\mathrm{p}<0.01)$ while there was no difference in HbA1c levels between the two genders. Total cholesterol and HDLcholesterol levels were higher in women $(\mathrm{p}=0.04$ and $\mathrm{p}<0.0001$, respectively) while triglycerides were significantly higher in men $(\mathrm{p}<0.0001)$. One-third of the participants were on continuous subcutaneous insulin infusion (CSII), with a significantly higher prevalence among women $(p=0.003)$. As expected, the presence of other autoimmune diseases was higher in women than in men $(44.9 \%$ vs. $25.4 \%, \mathrm{p}<0.0001)$. As to the prevalence of microvascular complications, only retinopathy was significantly higher in men than in women $(22.1 \%$ vs $15.2 \%$, $\mathrm{p}=0.038$ ). A history of CVD was present in $3.8 \%$ of the study cohort, without differences between genders.

Figure 1 shows the CVD risk classification of patients aged $<35$ or $\geq 35$ years, according to 2019 ESC guidelines. Among patients aged $<35$ years, $30 \%$ belonged to the very high risk category, the large majority $(62.5 \%)$ to the high risk category, and only as few as $7.5 \%$ to the moderate risk category. Among patients aged $\geq 35$ years, $68.2 \%$ belonged to the very high risk category, $31.8 \%$ to the high risk category and none was classified as being at moderate risk.

Table 2 reports the estimated 10-year CVD risk using the ST1RE prediction model within each category of risk defined by the 2019 ESC criteria. Among patients aged $<35$ years, all those in the moderate risk group were confirmed as such by the Steno predictive algorithm; however, among those classified in the high risk category by ESC, $100 \%$ were also at moderate risk according to the ST1RE prediction algorithm. Noteworthy, none of the 96 patients classified as being at very high risk by ESC were confirmed as such by ST1RE, only 1 was at high risk and all the others were at moderate risk.

Among patients aged $\geq 35$ years, none qualified as being at moderate risk according to ESC. In the high risk group according to ESC, only $8.1 \%$ was confirmed at high risk and as many as $92 \%$ had in fact a moderate risk according to ST1RE (Table 2). In the very high risk group according to ESC criteria, 12\% were predicted to be at very high risk, $28.9 \%$ at high risk and $59.1 \%$ at moderate risk according to the ST1RE. 


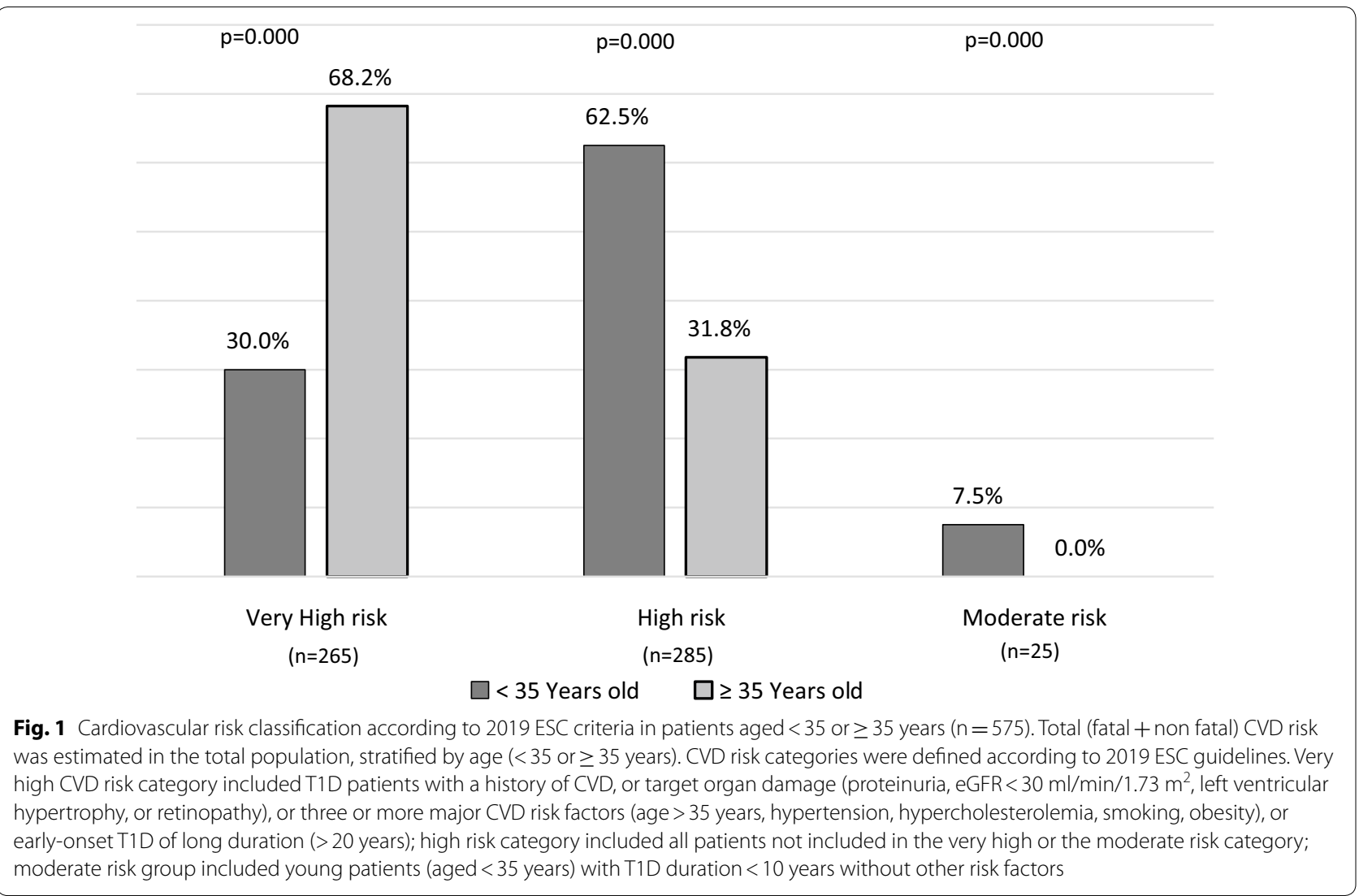

Table 2 10-year CVD risk prediction according to Steno type 1 Risk Engine (ST1RE) in a cohort of adults aged $<35$ or $\geq 35$ years in whom the CVD risk was classified according to 2019 ESC criteria $(n=532)$

\begin{tabular}{|c|c|c|c|}
\hline \multirow[t]{2}{*}{ CVD risk classification according to 2019 ESC guidelines } & \multicolumn{3}{|c|}{ 10-year CVD risk stratification predicted according to ST1RE } \\
\hline & Very high risk & High risk & Moderate risk \\
\hline \multicolumn{4}{|l|}{ Patients $<35$ years $(n=316)$} \\
\hline Very high risk $\mathrm{n}=96$ & $0(0)$ & $1(1)$ & $95(99)$ \\
\hline Target organ damage $n=26$ & $0(0)$ & $0(0)$ & $26(100)$ \\
\hline Three or more risk factors $n=5$ & $0(0)$ & $0(0)$ & $5(100)$ \\
\hline Early onset T1D of long duration ( $>20$ years) $n=50$ & $0(0)$ & $0(0)$ & $50(100)$ \\
\hline Two or more among the above criteria $n=15$ & $0(0)$ & $1(6.7)$ & $14(93.3)$ \\
\hline High risk $n=197$ & $0(0)$ & $0(0)$ & $197(100)$ \\
\hline Moderate risk $n=23$ & $0(0)$ & $0(0)$ & $23(100)$ \\
\hline \multicolumn{4}{|l|}{ Patients $\geq 35$ years $(n=216)$} \\
\hline Very high risk $n=142$ & $17(12)$ & $41(28.9)$ & $84(59.1)$ \\
\hline Target organ damage $n=23$ & $2(8.7)$ & $4(17.4)$ & $17(73.9)$ \\
\hline Three or more risk factors $n=49$ & $4(8.2)$ & $14(28.6)$ & $31(63.2)$ \\
\hline Early onset T1D of long duration ( $>20$ years) $n=10$ & $0(0)$ & $3(30)$ & $7(70)$ \\
\hline Two or more among the above criteria $\mathrm{n}=60$ & $11(18.3)$ & $20(33.3)$ & $29(48.4)$ \\
\hline High risk $n=74$ & $0(0)$ & $6(8.1)$ & $68(91.9)$ \\
\hline Moderate risk $n=0$ & $0(0)$ & $0(0)$ & $0(0)$ \\
\hline
\end{tabular}

Data are expressed as number ( $\mathrm{n}$ ) and percentage (\%). The analysis was performed in 532 patients since 22 patients had a previous CVD and 20 patients had some missing data

Target organ damage included proteinuria, eGFR $<30 \mathrm{ml} / \mathrm{min} / 1.73 \mathrm{~m}^{2}$, left ventricular hypertrophy, or retinopathy CVD risk factors were: age $>35$ years, hypertension, hypercholesterolemia, smoking, obesity 
Focusing on the ESC subcategories of very high risk patients aged $\geq 35$ years, $8.7 \%$ of patients classified as being at very high risk because of the presence of target organ damage and $8.2 \%$ of those with three or more $\mathrm{CV}$ risk factors were confirmed to be at very high risk according to ST1RE, while the large majority $(60-70 \%)$ of them was at moderate risk. Remarkably, among patients classified at very high risk because of early onset T1D of long duration ( $>20$ years), none was confirmed to be at very high risk, $30 \%$ was at high risk whereas the vast majority $(70 \%)$ had a predicted moderate risk according to ST1RE. A much larger proportion of patients (52\%) in the subcategory with two or more ESC criteria for the definition of a very high risk was confirmed to be at high or very high risk by ST1RE (Table 2).

Since from the analysis reported in Fig. 1 and Table 2, age appears to have a relevant impact on CVD risk, we decided to perform CVD risk prediction by ST1RE in patients classified according to 2019 ESC, limiting the analysis to those aged $\geq 50$ years. As shown in Fig. 2, the ESC risk classification performed much better in this age group, since $77 \%$ of patients at high/very high risk according to ESC were confirmed as such also by the ST1RE prediction score.

\section{Discussion}

\section{Evaluating CVD risk in T1D patients}

Recently, ESC-in collaboration with EASD-has issued the 2019 Guidelines on Diabetes, Pre-Diabetes and Cardiovascular Diseases, where CVD risk classification is proposed also for patients with T1D [17]. Noteworthy, however, CVD risk stratification for these patients has been largely based on observational studies [10] and never validated in relation to measured CVD events. In fact, there are very few controlled studies conducted in T1D individuals on the effect of treatment on CVD outcomes [31] or risks factors $[15,16]$. In the EMERALD (Effects of Metformin on CardiovasculaR function in AdoLescents with Type 1 diabetes) trial, metformin therapy as add-on to insulin improved insulin resistance and vascular health [16]. In contrast, the Adolescent Type 1 Diabetes Cardio-Renal Intervention Trial (AdDIT study) showed that the use of an ACE inhibitor and a statin did not change albumin - to-creatinine ratio (ACR), carotid intima-media thickness or other CVD markers in adolescents (10-16 years) with T1D, over a median period of 2.6 years [15]. Although these studies indicate some cardiovascular benefits of intervention on $\mathrm{CV}$ risk factors in primary prevention, they do not provide reliable information on how to identify T1D patients for whom the implementation of these treatments would be justified on the basis of a risk/benefit analysis. In fact, previous

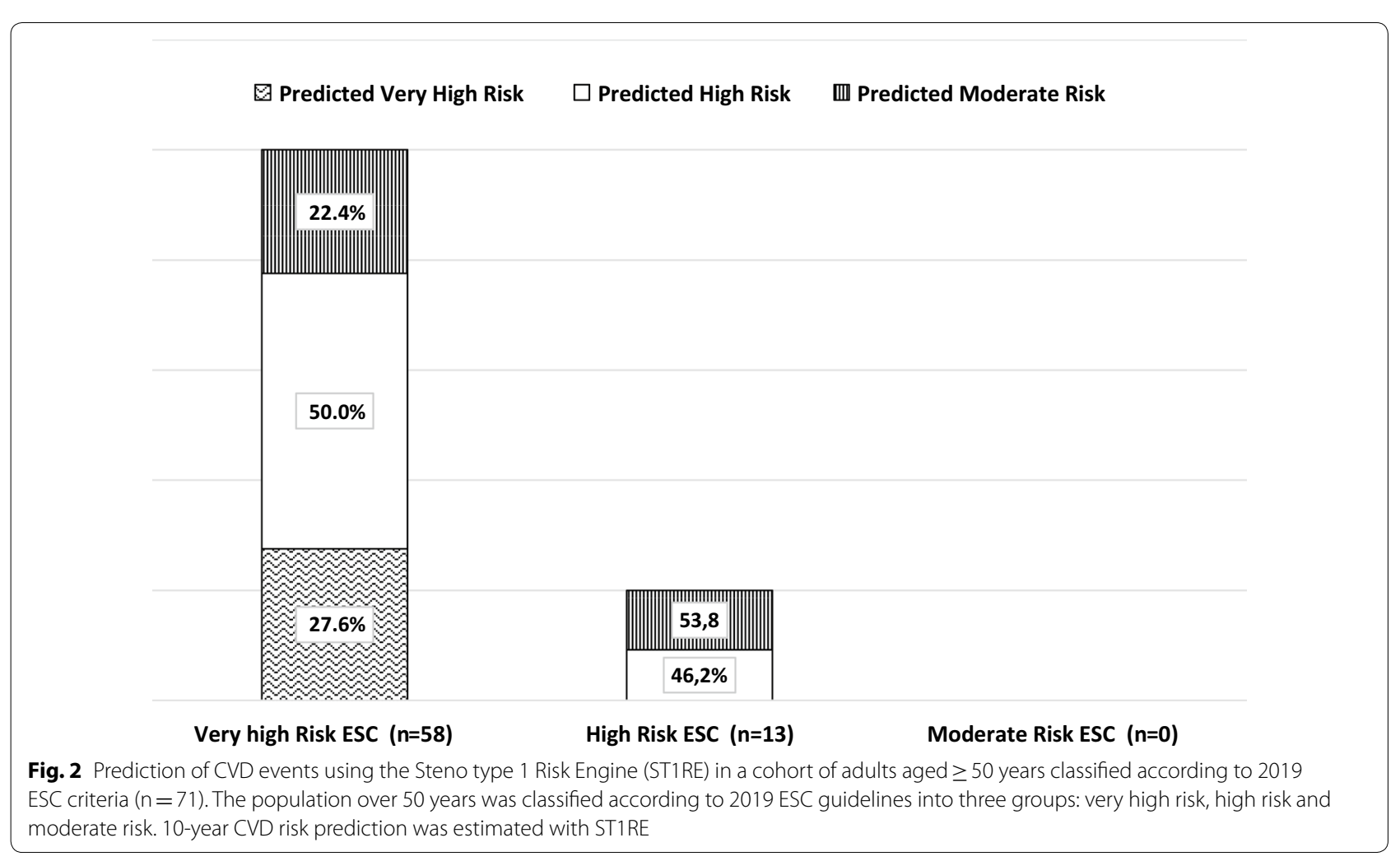


experience with T2D patients is of limited usefulness since different patterns of risk factors predict CVD in type 1 and type 2 diabetes [30-33]. Based on these premises, the American Diabetes Association (ADA) advices the implementation of predictive algorithms as a useful tool for T1D patients-specific CVD risk estimation [27]; among them, ST1RE represents one of the best options [23]. This is a model to predict 5- and 10-year CVD risk in adults with T1D, validated in the T1D population of the Funen Diabetes Database in Denmark; in addition, it was able to predict preclinical atherosclerosis in Spanish adults with T1D $[28,29]$. The Steno T1D risk score was able to identify individuals with subclinical atherosclerosis and high CVD risk also in a T1D population in Italy. However, the absolute risk was significantly overestimated despite the rather low number of events [34].

As far as we know, the present study is the first to evaluate CVD risk according to a prediction model (ST1RE) in an unselected real-life sample of adults with T1D without previous CVD, classified in relation to their presumed CVD risk according to 2019 ESC guidelines.

\section{Concordance between 2019 ESC risk classification and 10-year prediction of CVD risk by ST1RE}

The results of this study show poor concordance between the 2019 ESC risk classification in T1D patients and the predicted 10-year risk of a CVD event, as estimated by ST1RE. In fact, according to the ESC classification, as many as $45 \%$ of our patients without previous CVD events fell in the very high CVD risk category, but, according to ST1RE, only $12 \%$ of them had a predicted very high risk of CVD events in the subsequent 10 years. Notably, our patients were young (mean age $36 \pm 12$ years) and in a reasonable blood glucose control, had relatively well controlled blood pressure and plasma lipid levels, and a low prevalence of microvascular complications.

The lack of concordance was particularly large in subjects aged $<35$ years: it is remarkable that almost all patients (99\%) in this age group, classified in the very high risk category according to ESC, were only at moderate risk according to ST1RE. However, also among patients aged $\geq 35$ years, concordance was poor since the large majority (59\%) of those classified at very high risk according to ESC criteria was only at moderate risk according to ST1RE prediction, 29\% were at high risk and only as few as $12 \%$ were confirmed to be at very high risk.

We used the age cut-off of 35 years as suggested by ESC guidelines; nevertheless, stratifying the population according to an arbitrary higher cut-off (50 years) - as suggested by ESC for type 2 diabetes patients-, the concordance between the ESC CVD risk classification and the ST1RE 10-year CVD risk prediction becomes much better; in fact, among patients aged $\geq 50$ years, $78 \%$ of those classified in the very high risk category by ESC guidelines are confirmed to be at high/very high risk by the Steno algorithm (Fig. 2).

ESC guidelines largely emphasize early onset T1D of long duration as one of the major determinants of CVD risk events. In fact, they consider people with early onset T1D and $>20$ years duration in the same risk category as patients with a previous CVD event. The CVD predictive value of early onset diabetes and long diabetes duration is based on several cohort and registry studies [7, 35, 36]. In T1D subjects of the Swedish National Diabetes Register [7], the early onset of diabetes (1-10 years of age) was associated with a significantly higher risk of CVD events compared to T1D onset between the ages of 26-30 years [7], and resulted in loss of 17.7 years of life in women and 14.2 years in men [7]. In an observational study of an Australian cohort of 1169 T1D patients, Pease et al. showed a J-shaped association between diabetes duration and CVD, with a threshold effect at approximately 20 years [35]. In our study, among patients classified by ESC at very high risk because of early-onset T1D of long duration ( $>20$ years), none had a very high predicted risk according to ST1RE. Although the reason for this inconsistency remain unclear, it is reasonable to hypothesize that early onset T1D of long duration increases the predictive power for CVD events when associated to poor glycemic control. To this regard, measurement of HbA1c needs, probably, to be integrated with the novel metrics of glycemic control that have recently been introduced in clinical practice [37]; among these, high glycemic variability has emerged as an important determinant of vascular damage [38]. Future studies are needed to establish whether the inclusion of this parameter will improve the prediction of CVD risk in T1D patients.

In our population, target organ damage, multiple CVD risk factors or early onset diabetes of duration $>20$ years were not strong predictors of CVD events, if taken individually. On the contrary, the coexistence of two or more of these conditions in subjects $\geq 35$ years, identified people at high/very high risk, who were confirmed as such also using ST1RE.

\section{Clinical implications}

The assessment of CVD risk in T1D patients has important clinical implications, since different risk factors targets (especially LDL-cholesterol) and therapeutic strategies should be implemented in relation to CVD risk stratification [17]. Indeed, according to the ESC classification, around $45 \%$ of our cohort without previous CVD event $(n=238)$ should be aggressively treated with highintensity statins and antiplatelet agents, because at very high CVD risk. However, if we consider at very high risk 
only those confirmed by ST1RE, the number of patients to be aggressively treated would be much lower $(n=17)$. Our findings are in line with the ADA statement that not all T1D patients should be considered at the same CVD risk level and that, while a moderate hypolipidemic approach is indicated in younger subjects in primary prevention, a high-intensity statin therapy is required only in those aged 40-75 years, with multiple CVD risk factors [27]. The implementation of strategies with a more aggressive treatment of patients at higher risk while using moderate intensity therapies in those at lower risk is essential to maximize the efficacy for each individual patient and minimize the costs for the healthcare system.

\section{Strengths and limitations}

The main strengths of this study are: (1) the relatively large sample size of the cohort studied; (2) the adoption of standard diagnostic procedures, including physical examination, screening of chronic complications, central analysis of biochemical variables; (3) the evaluation of the predicted CVD risk performed by the ST1RE-a validated tool, specific for patients with T1D.

Some limitations should be acknowledged: firstly, the monocentric, observational study design and, secondly, the CVD risk evaluation was performed with a prediction model rather than by measuring hard endpoint (CVD events).

\section{Conclusions}

Our study shows a poor concordance between ESC risk classification and 10-year CVD risk predicted by ST1RE, at least in young patients with T1D. A greater accuracy of ESC risk classification was demonstrated in patients $\geq 50$ years of age. More studies are needed to validate predictive CVD risk algorithms versus event rates and to characterize clinical and metabolic features of T1D patients that identify those at very high CVD risk, in whom a very aggressive cardio-protective treatment would be justified.

\section{Abbreviations \\ BMI: Body mass index; SBP: Blood pressure; DBP: Diastolic blood pressure; CVD: Cardiovascular disease; ASCVD: Atherosclerotic Cardiovascular Disease (Ischemic heart disease, stroke, peripheral arteriopathy); eGFR: Estimated glomerular filtration rate; CSII: Continuous subcutaneous insulin infusion.}

\section{Acknowledgements}

We are indebted to all patients attending the Outpatients Diabetic Clinic and to the staff of the Diabetes Unit of Federico II University Hospital, Naples, Italy. We thank Rosanna Scala for the linguistic revision of this paper.

\section{Authors' contributions}

NT and MM drafted the manuscript. NT performed statistical analyses under the supervision of senior authors AAR, BC, MM and GR. RL, LB, GDP and LP acquired data, contributed to their analysis and interpretation. $A A R, B C, M M$ and GR designed the study, revised the article's intellectual content, and take full responsibility for the integrity of this work as a whole, including the study design, access to data, and the decision to submit and publish the manuscript. BC critically edited the manuscript. All authors read and approved the final manuscript.

\section{Funding}

This research did not receive any specific funding.

\section{Availability of data and materials}

Data collected for this study can be shared and made available upon reasonable request to the corresponding author and subject to an approved proposal and data access agreement.

\section{Ethics approval and consent to participate}

The local Ethics Committee approved the study protocol, and the study was carried out in accordance with Declaration of Helsinki. Each participant signed a written informed consent.

\section{Consent for publication}

Not applicable.

\section{Competing interests}

All Authors report no competing interests in relation to this study.

\section{Author details}

${ }_{1}^{1}$ Department of Clinical Medicine and Surgery, Federico II University, Via S. Pansini 5, 80131 Naples, Italy. ${ }^{2}$ Department of Molecular Medicine and Medical Biotechnology, Federico II University, Naples, Italy.

Received: 29 June 2020 Accepted: 23 September 2020

Published online: 03 October 2020

\section{References}

1. Patterson CC, Karuranga S, Salpea P, et al. Worldwide estimates of incidence, prevalence and mortality of type 1 diabetes in children and adolescents: results from the International Diabetes Federation Diabetes Atlas, 9th edition. Diabetes Res Clin Pract. 2019;157:107842.

2. Lind M, Svensson AM, Kosiborod M, Gudbjornsdottir S, Pivodic A, Wedel $\mathrm{H}$, et al. Glycemic control and excess mortality in type 1 diabetes. N Engl J Med. 2014;371:1972-82

3. Jørgensen ME, Almdal TP, Carstensen B. Time trends in mortality rates in type 1 diabetes from 2002 to 2011. Diabetologia. 2013;56(11):2401-4.

4. Petrie D, Lung TW, Rawshani A, Palmer AJ, Svensson AM, Eliasson B, et al. Recent trends in life expectancy for people with type 1 diabetes in Sweden. Diabetologia. 2016;59(6):1167-76.

5. Diabetes Control and Complications Trial (DCCT)/Epidemiology of Diabetes Interventions and Complications (EDIC) Study Research Group. Mortality in type 1 diabetes in the DCCT/EDIC versus the general population. Diabetes Care. 2016;39:1378-83.

6. Lee YB, Han K, Kim B, Lee S-E, Jun JE, Ahn J, et al. Risk of early mortality and cardiovascular disease in type 1 diabetes: a comparison with type 2 diabetes, a nationwide study. Cardiovasc Diabetol. 2019;18:157.

7. Rawshani A, Sattar N, Franzen S, Rawshani A, Hattersley AT, Svensson AM, et al. Excess mortality and cardiovascular disease in young adults with type 1 diabetes in relation to age at onset: a nationwide, register-based cohort study. Lancet. 2018;392:477-86.

8. Schäfer M, Nadeau KJ, Reusch JEB. Cardiovascular disease in young People with type 1 diabetes: search for cardiovascular biomarkers. J Diabetes Complications. 2020. https://doi.org/10.1016/j.jdiacomp.2020.107651 (published online ahead of print, 2020 Jun 6).

9. Diabetes Control and Complications Trial (DCCT)/Epidemiology of Diabetes Interventions and Complications (EDIC) Study Research Group. Intensive diabetes treatment and cardiovascular outcomes in type 1 diabetes: the DCCT/EDIC Study 30-year follow-up. Diabetes Care. 2016;39:686-93.

10. Rawshani A, Rawshani A, Sattar N, Franzén S, McGuire DK, Eliasson B, et al. Relative prognostic importance and optimal levels of risk factors for mortality and cardiovascular outcomes in type 1 diabetes mellitus. Circulation. 2019;139:1900-12. 
11. Sousa GR, Pober D, Galderisi A, Lv H, Yu L, Pereira AC, et al. Glycemic control, cardiac autoimmunity, and long- term risk of cardiovascular disease in type 1 diabetes mellitus: a DCCT/EDIC cohort-based study. Circulation. 2019;139:730-43.

12. Shah VN, Bailey R, Wu M, Foster NC, Pop-Busui R, Katz M, et al. T1D exchange registry risk factors for cardiovascular disease (CVD) in adults with type 1 diabetes: findings from prospective real-life T1D Exchange Registry. J Clin Endocrinol Metab. 2020;105:1-7.

13. Hägg-Holmberg S, Dahlström EH, Forsblom CM, et al. The role of blood pressure in risk of ischemic and hemorrhagic stroke in type 1 diabetes. Cardiovasc Diabetol. 2019;18(1):88.

14. Garofolo M, Gualdani E, Giannarelli R, Aragona M, Campi F, Lucchesi D, Daniele G, Miccoli R, Francesconi P, Del Prato S, Penno G. Microvascular complications burden (nephropathy, retinopathy and peripheral polyneuropathy) affects risk of major vascular events and all-cause mortality in type 1 diabetes: a 10-year follow-up study. Cardiovasc Diabetol. 2019;18:159.

15. Marcovecchio ML, Chiesa ST, Bond S, et al. ACE inhibitors and statins in adolescents with type 1 diabetes. N Engl J Med. 2017;377(18):1733-45.

16. Bjornstad $P$, Schäfer $M$, Truong $U$, et al. Metformin improves insulin sensitivity and vascular health in youth with type 1 diabetes mellitus. Circulation. 2018;138(25):2895-907.

17. Cosentino F, Grant PJ, Aboyans V, Bailey CJ, Ceriello A, Delgado V, et al. 2019 ESC Guidelines on diabetes, pre-diabetes, and cardiovascular diseases developed in collaboration with the EASD. Eur Heart J. 2020;41:255-323.

18. Mach F, Baigent C, Catapano AL, Koskinas KC, Casula M, Badimon L, et al. 2019 ESC/EAS guidelines for the management of dyslipidaemias: lipid modification to reduce cardiovascular risk. Eur Heart J. 2020;41:111-88.

19. Cederholm J, Eeg-Olofsson K, Eliasson B, Zethelius B, Gudbjörnsdottir S. A new model for 5-year risk of cardiovascular disease in Type 1 diabetes; from the Swedish National Diabetes Register (NDR). Diabet Med. 2011:28:1213-20.

20. Hippisley-Cox J, Coupland C, Brindle P. Development and validation of QRISK3 risk prediction algorithms to estimate future risk of cardiovascular disease: prospective cohort study. BMJ Clin Res. 2017;357:2099.

21. Miller RG, Anderson SJ, Costacou T, Sekikawa A, Orchard TJ. Hemoglobin A1c level and cardiovascular disease incidence in persons with type 1 diabetes: an application of Joint Modeling of Longitudinal and Time-toEvent Data in the Pittsburgh Epidemiology of Diabetes Complications Study. Am J Epidemiol. 2018;187:1520-9.

22. Soedamah-Muthu SS, Vergouwe Y, Costacou T, Miller G, Zgibor J, Chaturvedi $\mathrm{N}$, et al. Predicting major outcomes in type 1 diabetes: a model development and validation study. Diabetologia. 2014;57:2304-14.

23. Vistisen D, Andersen GS, Hansen CS, Hulman A, Henriksen JE, BechNielsen $\mathrm{H}$, et al. Prediction of first cardiovascular disease event in type 1 diabetes mellitus: the Steno Type 1 Risk Engine. Circulation. 2016;133:1058-66.

24. Marcovecchio ML, Dalton RN, Daneman D, Deanfield J, Jones TW, Neil $\mathrm{AH}, \mathrm{On}$ behalf of the Adolescent type 1 Diabetes cardio-renal Intervention Trial (AdDIT), et al. A new strategy for vascular complications in young people with type 1 diabetes mellitus. Nat Rev Endocrinol. 2019:15:429-35.
25. Bachmann KN, Wang TJ. Biomarkers of cardiovascular disease: contributions to risk prediction in individuals with diabetes. Diabetologia. 2018;61:987-95.

26. American Diabetes Association. Standards of Medical Care in Diabetes-2020. Diabetes Care. 2020;43(supplement 1):S11.

27. Viñals C, Conget I, Pané A, Boswell L, Perea V, Blanco AJ, et al. Steno type 1 risk engine and preclinical atherosclerosis in Mediterranean individuals with type 1 diabetes. Diabetes Metab Res Rev. 2020. https://doi. org/10.1002/dmrr.3320.

28. Llauradó G, Cano A, Albert L, Ballesta S, Mazarico I, Luchtenberg MF, González-Sastre M, et al. Arterial stiffness is highly correlated with the scores obtained from the Steno Type 1 Risk Engine in subjects with T1DM. PLOS ONE. 2019;14(9):e0220.

29. Williams B, Mancia G, Spiering W, Agabiti Rosei E, Azizi M, Burnier M, et al. 2018 ESC/ESH Guidelines for the Management of Arterial Hypertension. Eur Heart J. 2018;39:3021-104.

30. de Ferranti S, de Boer IH, Fonseca V, Fox CS, Sherita SH, Lavie CJ, et al. Type 1 diabetes mellitus and cardiovascular disease: a scientific statement from the American Heart Association and American Diabetes Association. Diabetes Care. 2014:37:2843-63.

31. Collins R, Armitage J, Parish S, Sleigh P, Peto R, Heart Protection Study Collaborative Group. MRC/BHF Heart Protection Study of cholesterol lowering with simvastatin in 5963 people with diabetes: a randomised placebo-controlled trial. Lancet. 2003;361:2005-16.

32. Schnell O, Cappuccio F, Genovese S, Standl E, Valensi P, Ceriello A. Type 1 diabetes and cardiovascular disease. Cardiovasc Diabetol. 2013;12:156.

33. Collier A, Ghosh S, Hair M, Waugh N. Gender differences and patterns of cardiovascular risk factors in Type 1 and Type 2 diabetes: a populationbased analysis from a Scottish region. Diabet Med. 2015;32:42-6.

34. Boscari F, Morieri ML, Amato AML, et al. Performance of the Steno type 1 risk engine for cardiovascular disease prediction in Italian patients with type 1 diabetes. Nutr Metab Cardiovasc Dis. 2020. https://doi. org/10.1016/j.numecd.2020.07.006 (published online ahead of print, 2020 Jul 11)

35. Pease A, Earnest A, Ranasinha S, Nanayakkara N, Liew D, Wischer N, et al Burden of cardiovascular risk factors and disease among patients with type 1 diabetes: results of the Australian National Diabetes Audit (ANDA). Cardiovasc Diabetol. 2018;7(1):77.

36. Morimoto A, Onda Y, Nishimura R, Sano H, Utsunomiya K, Tajima N. Cause -specific mortality trends in a nationwide population-based cohort of childhood-onset type 1 diabetes in Japan during 35 years of follow-up: the DERI mortality study. Diabetologia. 2013;56:2171-5.

37. Danne T, Nimri R, Battelino T, Bergenstal RM, Close KL, DeVries JH, et al. International consensus on use of continuous glucose monitoring. Diabetes Care. 2017:40:1631-40.

38. Ceriello A, Monnier L, Owens D. Glycaemic variability in diabetes: clinical and therapeutic implications. Lancet Diabetes Endocrinol. 2018;7:221-30.

\section{Publisher's Note}

Springer Nature remains neutral with regard to jurisdictional claims in published maps and institutional affiliations.

\footnotetext{
Ready to submit your research? Choose BMC and benefit from:

- fast, convenient online submission

- thorough peer review by experienced researchers in your field

- rapid publication on acceptance

- support for research data, including large and complex data types

- gold Open Access which fosters wider collaboration and increased citations

- maximum visibility for your research: over 100M website views per year
}

At $\mathrm{BMC}$, research is always in progress.

Learn more biomedcentral.com/submissions 